\title{
Variations in Arabic Reading Skills between Normally Achieving and at Risk for Reading Disability Students in Second and Fourth Grades
}

\author{
Mahmoud Emam ${ }^{1}$, Ali Kazem ${ }^{1}$, Taghreed Al-Said ${ }^{1}$, Watfa Al-Maamary ${ }^{2}$ \& Raya Al-Mandhari ${ }^{1}$ \\ ${ }^{1}$ College of Education, Department of Psychology, Sultan Qaboos University, Sultanate of Oman \\ ${ }^{2}$ Sultan Qaboos University Hospitals, Sultanate of Oman \\ Correspondence: Mahmoud Emam, College of Education, Department of Psychology, Sultan Qaboos University, \\ P.O. Box 32, Al Khod 123, Muscat, Sultanate of Oman. E-mail: memam@squ.edu.om
}

\author{
Received: June 11, 2014 Accepted: July 18, 2014 Online Published: August 15, 2014 \\ doi:10.5539/res.v6n3p17 URL: http://dx.doi.org/10.5539/res.v6n3p17
}

\begin{abstract}
The study investigated variations in Arabic reading skills between normally achieving students and students at risk for reading disability in second and fourth grades. Using a cross-sectional design the study tested the effect of gender, grade level, and student condition on the variation of Arabic reading skills. Participants were 381 Arabic speaking children from second and fourth grades. Participants included both normally achieving students and students who were referred to the Learning Disabilities Unit in elementary schools in Oman. Dependent measures of the study included letter sound identification (LSI), word decoding (WD), phonological awareness (PA) through blending and segmentation, word recognition (WR), reading comprehension (RC), and listening comprehension (LC) in Arabic. Multivariate analysis indicated that gender, grade level and student condition had an effect on variation of reading skills. Additionally, the interaction effect of grade level and student condition as well as the combination of the three independent variables showed similar effects. Significant reading skills varied according to gender, grade level and student condition in addition to the interaction effects. WD, LSI and LC were significant as a result of the interaction effects. The results are discussed in relation to the characteristics of the Arabic language orthography.
\end{abstract}

Keywords: reading skills, reading disabilities, Arabic orthography

\section{Introduction}

Acquisition of well-developed literacy skills is a critically important developmental landmark for children. A substantial body of research highlights the drawbacks associated with delayed or disordered acquisition of reading skills (Al-Otaiba \& Fuchs, 2006). Children who are poor readers tend to continue to struggle with literacy skills, and read less than their peers who are more skilled in reading. As a consequence, children who are poor readers tend to receive less practice in reading and less exposure to content knowledge, vocabulary, and other language skills than do children who are more skilled in reading (Lonigan, Alan, \& Lerner, 2011; Cunningham \& Stanovich, 1998). Reading and reading-related skills are likely to remain stable from an early point in school (Wagner et al., 1997). Longitudinal studies indicate that children who are poor readers by the end of the first grade almost never acquire average-level reading skills by the end of elementary school without substantial and sustained remediation efforts (Al-Otaiba \& Fuchs, 2006; Francis, Shaywitz, Stuebing, Shaywitz, \& Fletcher, 1996).

One of the most influential models of reading is the Triangle Model (Plaut et al. 1996), which provides a framework for conceptualizing the development of reading skills. According to the TR which consists of three nodes that form a triangle, the process of reading relies on orthographic, phonological and semantic representations. The model proposes that successful reading is achieved through activation of phonological information, semantic information, or both. The role of phonological representations in learning to read has been highlighted in different orthographies including Arabic (Mahfoudhi, Elbeheri, Al-Rashidi, \& Everatt, 2010; Elbeheri \& Everatt, 2007). Furthermore, a substantial body of research supports the proposal that difficulties with phonological representations are at the root of reading disabilities including dyslexia (Snowling, 2000). To date, there have been a number of studies which examined phonological awareness for Arabic-speaking students (Taibah \& Haynes, 2011; Mahfoudhi, Elbeheri, Al-Rashidi, \& Everatt, 2010). There has been, however, less focus on the comparison of the performance of poor and skilled readers on key reading skills as students grow 
and progress from early to later grades in the elementary school. The variations in such performance are likely to highlight the most important as well as influential reading skills for learning Arabic elementary grades. The current study aims to fill this gap by exploring the performance of second and fourth grade students who are poor readers versus those who are skilled reads on a wide range of reading skills.

\subsection{Reading Skills}

The difference between poor and skilled readers is essentially a difference in skill acquisition (Al Otaiba \& Fuchs). A number of reading skills contribute to the variation in the performance of poor and skilled readers. These include phonological awareness, decoding abilities, oral reading fluency, reading comprehension and listening comprehension (Lonigan, Burgess, \& Anthony, 2000).

Metaanalytic studies on the predictive relation between a skill measured in preschool or kindergarten and reading outcomes (i.e., word decoding, reading comprehension, spelling) for children learning to read in an alphabetic language indicated that children's skills related to print knowledge such as alphabet knowledge and print concepts; phonological processing skills including phonological awareness, phonological access to lexical store, and phonological memory; and aspects of oral language including vocabulary, syntax/grammar, and word knowledge were substantive and independent predictors of children's later reading outcomes (Schatschneider \& Westberg, 2008). Results of longitudinal studies with young children revealed a high degree of continuity between the levels of reading-related skills displayed by preschool children and the levels of reading-related and reading skills displayed by these children when they join elementary school (Lonigan, Burgess, \& Anthony, 2000; Storch \& Whitehurst, 2002). This reflects that the developmental antecedents that lie behind the acquisition of reading develop early and prior to the onset of formal schooling (Lonigan, Alan, \& Lerner, 2011).

Of the different reading skills mentioned above, the influence of phonological awareness on reading accuracy is irrefutable. A number of studies have shown that phonological awareness skills are indicative of reading ability (Bryant 1998). Alternatively, debates continue about the relative importance of different phonological units in predicting reading skills. Some researchers argue that rhyming skills are crucial (Goswami 2001) and others emphasize the relative importance of the phoneme (Hulme et al. 2002). Generally, phonological awareness is understood as a person's awareness of the sound structure of spoken words. It has proven to be a good indicator of later reading ability in children in many languages (Gillon, 2004; Goulandris, 2003). In Arabic phonological awareness is also a key variable in reading acquisition and a critical skill that children must master to be skilled readers of both vocalized and unvocalized text (Taibah \& Haynes, 2011). According to Abu Rabia, Share, and Mansour (2003) phonological awareness is one of the important introductory steps to reading in general and reading in Arabic specifically. Since Arabic is a phonetically written language being able to pronounce letter sounds is one of the strategies that helps new readers decode the words they do not recognize by sight. This phonetic approach is considered recent in terms of teaching strategies, when compared to the "spelling way" which it was widely used in the 19th century (Tahan, Cline, \& Messaoud-Galusi, 2011) and is still used. Abu-Rabia, Share and Mansour, in a 2003 study investigating word identification in Arabic and basic cognitive processes in reading-disabled (RD) and normal readers of the same age and younger normal readers who were the same level as the $\mathrm{RD}$ readers highlighted the key role of phonological awareness in Arabic reading process.

Furthermore, phonological decoding ability is essential in the process of reading acquisition (Abu-Rabia, 2001). It is well established in the literature that measuring the pseudoword reading is the benchmark test of children's phonological decoding skill (Abu-Rabia, 1995). A number of studies have been conducted using pseudowords as their phonological decoding measure among normal readers and children with reading disabilities (RD). The difficulty which children with RD experience during reading pseudowords seems to be "the result of deficiencies in their basic phonological processing" (Abu-Rabia, Share, \& Mansour, 2003, p. 426). In their discussion of the results of their 2003 study Abu Rabia, Share and Mansour advocate that children with RD in Arabic generally showed characteristics of poor phonological processing, poor working memory skills, and poor syntactic skills, which were similarly echoed in previous research on phonological awareness in other languages. However, children with RD tended to show strong visual-orthographic patterns of reading from an early age. According to Abu-Rabia and his colleagues, phonology seems to be extremely powerful, followed by morphology and visual memory. Syntax and working memory are also important, although they show less consistency (Abu-Rabia, Share, \& Mansour, 2003). In 2011, Taibah and Haynes carried out a cross sectional study on the contributions of phonological processing - defined as phonological awareness (the capacity to reflect on the sound structure of spoken words), rapid naming (RAN) (capacity to retrieve phonological codes stored in memory) and phonological memory (processing resource of limited capacity involved in the preservation of information) - to decoding and fluency skills in Arabic among 237 Arabic speaking children in Grades K-3 in Saudi Arabia (Taibah \& Haynes, 2011). Results showed that at each grade phonological processing skills correlated 
significantly with all reading skills at a range from moderate to high. Indeed, the study showed that readers lacking automaticity relied more on phonological awareness than rapid naming capacity or phonological memory. The predictive power of rapid naming increased in grades 2 and 3 and the predictive power of phonological awareness decreased in grade 2 although was still more powerful than rapid naming. "These findings are consistent with the view that fluency in the beginning grade levels relies on accuracy of decoding - a skill highly dependent on phonological awareness. In parallel, as children progress to second and third grades and develop decoding that is more automatic, the predictive power of RAN increases" (Taibah \& Haynes, 2011, pp. 1036-1037).

Similarly, a substantial body of research has demonstrated that skills that are related to mapping sounds to letters (i.e., phonological awareness and letter knowledge) play vital roles in learning to read and write in languages with alphabetic writing systems (Muter, Hulme, Snowling, \& Stevenson, 2004). While several studies were conducted with English-speaking children, a growing number of studies suggest that these skills are similarly involved in literacy acquisition different orthographies (Kim, 2009; de Jong \& van der Leij, 1999). However, these previous studies tended to focus on accuracy (e.g., phonological awareness accuracy predicting word reading) rather than the fluency (accuracy and rate) of componential skills. Furthermore, less known is longitudinal relationships between critical componential skills and reading skills, particularly in a language other than English. In Arabic, which is described as "abjads," or consonantal orthographies, letters are used to represent consonants, and vowels are denoted with diacritics markings (dots or lines) placed above or below the consonants. 3 Words are derived from two- or three-consonant root morphemes, and vowels and affixes are added to these roots to create variations of meaning and denote parts of speech (Abu Rabia, 2012; Azzam, 1993).

Findings from early large-scale studies of reading achievement suggested consistent but moderate correlations between children's oral language and reading (Whitehurst \& Lonigan, 2001). For instance, Share, Jorm, Maclean, and Matthews (1984) conducted a study on kindergarteners and first graders and found that the correlations between oral language (vocabulary and syntax) and reading were significantly high. Despite these results, the key conclusion of researchers in early studies of this type was that phonological and phonemic awareness were the main determinants of reading skill. Often, oral language was only considered as a control variable, or as a proxy for verbal intelligence, and not as an important contributor to reading in its own right. Proponents of more complex views of oral language have argued that many of these early studies, because of their reliance on receptive vocabulary as the primary measure of oral language, underestimate the role of oral language for reading (Dickinson, McCabe, Anastasopoulos, Peisner-Feinberg, \& Poe, 2003).

This has led researchers to advocate that using more comprehensive measures of oral language that include receptive vocabulary but also tap expressive vocabulary, listening comprehension, and in some cases, oral narrative skill show stronger links between oral language and literacy, especially when reading is measured in the mid-primary school years. With a sample of 74 low-income children, Tabors, Snow, and Dickinson, (2001) found that both receptive vocabulary and narrative production in kindergarten predicted reading comprehension in Grade and Grade 7. However, children's early literacy skills in this study also predicted their later reading comprehension at Grades 4 and 7, and vocabulary, narrative, and early literacy were intercorrelated in kindergarten. This study did not address whether oral language measures uniquely predicted children's reading comprehension after taking early literacy abilities into account. The studies reviewed above has informed the current study in terms of exploring the links among a different array of reading skills in Arabic comparing between poor and skilled readers in two different grade levels.

\subsection{Current Study}

\subsubsection{The Arabic Language System}

Arabic is a language of 28 letters (or 29 the hamza is counted, a glottal stop usually represented by a diacritical mark). It is written from right to left and the letters take different forms based on their position within the word-initial, medial or terminal, but letter shape is generally consistent and therefore recognizable. Many letters are similar in shape, differentiated only by the number of dots they carry; dots are part of the orthography of 15 letters, 10 of which have one dot (above or below), 3 of which have two dots (above or below) and two of which have three dots (above). There are three long vowels among the 28 letters; the rest are consonants (Elbeheri, 2005).

The significance of this system of using diacritical marks or vocalizing letters is that most Arabic texts are not written with the short vowels - they are unvocalized or unvoweled. In general, vocalization is retained in school texts through the third or fourth grade. The elimination of the diacritical marks creates a challenge for the Arabic reader as he or she progresses through school. It also suggests that an understanding of how children transition 
from vocalized to unvocalized text successfully is of paramount importance and it is critical to understand the strategies that children use to process and make sense of unvocalized text. In other words, the explicitness of instructional strategies that help readers transition into unvocalized text remains a line of inquiry. In other words, when text is vocalized Arabic has what is called a transparent or shallow orthography. With the short vowel marks in place, one can identify and pronounce words correctly. Without the vowel marks in place readers are forced to rely primarily on word morphology, syntax and context within the sentence to determine certain words (Taouk \& Coltheart, 2004).

In an early study on the impact of vocalization on reading accuracy (Abu-Rabia \& Siegel, 1995), 40 eighth-grade Arab students read vocalized and unvocalized words in isolation and in a context. Reading accuracy was significantly improved when readers (both poor and strong) read the vocalized text, although skilled readers showed greater improvement. Both skilled and poor readers significantly improved their reading accuracy when they read vocalized and unvocalized words in context, however skilled readers improved more than poor readers. Another study was conducted by Abu-Rabia (1995) on 143 Arab children (8-11 years old) learning to read in Arabic demonstrated that word recognition was highly correlated with phonological skills, semantic processing, syntactic knowledge and short-term memory. The findings unambiguously pointed to phonological skills, especially knowledge of grapheme-phoneme conversion rules, as a significant factor of reading in Arabic because they facilitate the rapid decoding of words. Struggling readers showed lower phonological and semantic processing levels than the stronger readers.

Furthermore, Abu-Rabia (1997) subsequently looked at the impact of vowels (vocalization) and context on the reading accuracy of 109 poor and skilled native Arabic readers in the 10th grade. He used narrative stories and newspaper articles, having the subjects read aloud vocalized and unvocalized lists of words as well as paragraphs. This research demonstrated that vocalization and context were key variables that aided word recognition and reading accuracy for both poor and skilled readers, no matter which kind of text (story or news article) the subjects were reading. Abu-Rabia concluded that vocalized materials provided additional phonological information to readers that aided in word recognition - and helped readers avoid homographic confusion (i.e. where two different words look exactly alike when they are unvocalized) - as well as reading accuracy and comprehension for both poor and skilled readers.

Abu-Rabia (2001) looked at the impact of vocalization and context on the reading accuracy and comprehension of adult native Arabic speakers (22-30 years old) in both Arabic and Hebrew, which was their second language. (Hebrew also utilizes a system of vocalization.) All of the subjects were skilled readers in Arabic. The results showed that vocalized text in both languages were read and comprehended significantly better than unvocalized text. In addition, accuracy of the readers was significantly improved by sentence context in cases where the text was unvowelled. With vocalized text, readers did not have to rely on context to distinguish homographic words. Abu-Rabia also concluded in turn that consonantal patterns of words (i.e. word morphology and visual-orthographic elements) were important for reading unvocalized material with comprehension.

\subsubsection{Teaching Arabic in Schools in the Sultanate of Oman}

Arabic has been described as diglossic, having a "high" Modern Standard Arabic (MSA) and a low (ammiyya [everyday dialect]) form (Ibrahim \& Aharon-Peretz, 2005). Ammiyya is a spoken dialect - it is a mother tongue - while fus-ha is learned, usually in school and is the language of reading and writing. Thus, referring to Arabic as a mother tongue or native language is complex because most speakers do not speak formal Arabic(MSA) or fus-ha--in daily life. While this is the bridge language of the Arab world, children learn to speak in a variation of formal Arabic - a dialect (ammiyya), whose features (pronunciation, vocabulary and grammatical structures etc.) differ, sometimes significantly, from MSA (Saiegh-Haddad, 2003).

The Sultanate of Oman is moving towards transferring public schools to be inclusive schools which provide special education services to students with special educational needs (SEN). Statistics of the Department of Special Education at the Ministry of Education $(\mathrm{MoE})$ in Oman show that the number of students referred for LD in inclusive schools has increased significantly in the last decade. The number of students referred for having RDs represents $80 \%$ of the total number of referrals. Schools have set up an LD Unit in which referred students receive support. By an Educational Mandate in 2007 which was issued in accordance with the Omani Children with Disabilities Care and Rehabilitation Act in 1996 that was reauthorized in 2008, children referred for having $\mathrm{RD}$ became eligible for receiving additional help through tasks that are given by the special education teachers who hold a specialized one year Higher Diploma in LDs, a program which is tailored by Sultan Qaboos University to fulfill the training needs of the Ministry of Education professionals in the Sultanate of Oman (Emam, 2012). In Oman, curriculum and Arabic teaching strategy do not typically include phonological 
awareness but depend on the alphabetical method or letter name identification. The present study was conducted as part of a larger strategic research project that examined the identification and intervention of students with RDs in grades 1-6 in Oman. The larger strategic project aimed also to develop an optimal framework which promotes explicit instruction on emergent literacy skills such as phonological awareness, phonics skills, vocabulary building, oral reading, and reading comprehension (Emam, 2012).

The goal of the present study was to expand our understanding of reading acquisition for Arabic speaking poor and skilled readers elementary school students in Oman by investigating variation in students' performance on critical skills of a deep orthography, Arabic, including letter sound identification, word decoding, phonological awareness, word recognition, reading comprehension and listening comprehension. We additionally aimed at investigating the effect of grade level, gender, and condition of students (normally achieving students and students at risk for reading disabilities) on the acquisition of these skills. The following two research questions were examined:

- What are the effects of gender, grade level, and student condition on students' acquisition of critical reading skills of Arabic including letter sound identification, word decoding, phonological awareness, word recognition, reading comprehension and listening comprehension?

- What are the are the effects of the interactions between the independent variables of gender, grade level, and student condition on students' acquisition of critical reading skills of Arabic including letter sound identification, word decoding, phonological awareness, word recognition, reading comprehension and listening comprehension?

\section{Method}

\subsection{Participants}

Participants included 420 students from grades two and four whose native language is Arabic (Table 1). The data were collected from different schools representing the 11 demographic areas in Oman: North, Middle, Southeast, and Southwest. Arabic language instruction started in grade 1 and placed heavy emphasis on phonics and vocabulary instruction. Across the different schools, curricular goals and objectives, materials, and reading instruction methods were similar. All classes were taught in Arabic. Students from both grades were chosen randomly for both conditions (NA and RD) and consent forms were sent to parents seeking their agreement of participation. Of the 420 of the chosen students enrolled across all schools, 381were included in the study, based on parental consent Table1 presents and overview of all participants. The students ranged in age from 7.33 to 9.25 years and came from Arabic ethnic backgrounds and from families in which both parents spoke Arabic at home. None had sensory problems that interfered with learning. Children of expats were excluded from the study and only Omani participants were included.

Table 1. Overview of the participants 1

\begin{tabular}{llllll}
\hline Condition & Gender & Grade 2 & Grade 4 & Total \\
\hline \multirow{2}{*}{ ARDs } & Male & 46 & 85 & 131 & 213 \\
& Female & 33 & 49 & 82 & 78 \\
\multirow{2}{*}{ NA } & Male & 30 & 48 & 90 & 168 \\
\multirow{2}{*}{ Total } & Female & 38 & 52 & 381 \\
\hline
\end{tabular}

Note: $\mathrm{NA}=$ Normally Achieving pupils; ARDs= At Risk for Reading Disabilities

\subsection{Materials and Instruments}

Tests were developed in the areas of literacy and phonological awareness (PA). The literacy areas included word recognition, reading comprehension, and listening comprehension. Adaptation of measures to Arabic were carried out through the use of a forward-translation design (Hambleton, 2002), which focuses on both the sourceand target-language versions of the test. Modern Standard Arabic (MSA), the language of most books and instruction, was used in all measures. In Oman, there are numerous spoken dialects in the Arabic language that vary from MSA. Reliability and validity issues were considered before administering the measures. The children were tested by specialist LD teachers who received training as part of a strategic project in Oman on 
identification and intervention for children at risk for reading difficulties. All tests were administered individually in a quiet context at each school. Each student had one to two sessions (no more than 35 min per session). The teachers verified with the students their capability to continue the tests in one session.

\subsubsection{Letter Sound Identification (LSI)}

This measure was developed for Arabic emulating the same scoring procedures as are employed in Early Grade Reading Assessment (EGRA, USAID, 2011). Items were developed based on the frequency of letters in the Arabic curriculum. Also included were the word-middle form of Arabic letters, which differ slightly from the word-initial shape of letters. The list of letters and letter combinations were arranged in a table consisting of 90 phonemes for grade two and 130 phonemes for grade four. The phonemes included consonants, vowels, and consonant vowel combinations. The difficulty of phonemes increased with length. Cronbach's alpha was employed to allow identification and deletion of items of superfluous difficulty or that had low or negative correlations with overall performance. The Cronbach's alpha was (0.98) for the second grade items and (0.99) for the fourth grade items.

\subsubsection{Word Recognition (WR)}

This measure was developed for Arabic emulating the same scoring procedures as are employed for the Dynamic Indicators of Basic Early Literacy Skills (DIBELS). Items were developed based on the frequency of letters and words in the Arabic curriculum. Also included were the word-middle form of Arabic letters, which differ slightly from the word-initial shape of letters. The list of words included nouns and verbs. The difficulty of words, however, increased with word length, diminishing frequency, and reduction of the number of short vowels (devowelization). The gradual reduction of short vowels represents an incremental transition from shallow orthography words to deep orthography words. Non-vowelized Arabic words can be read differently (diverse meanings), but correctly. Because the WR test presented words in isolation, the non-vowelized words included only words that had exactly the same pronunciation and meaning in their vowelized or non-vowelized forms. The test initially included 30 items. Cronbach's alpha was employed to allow identification and deletion of items of superfluous difficulty or that had low or negative correlations with overall performance. The Cronbach's alpha was (0.96) for the remaining 20 items in the final version of the WR test for the second grade items and (0.99) for fourth grade items.

\subsubsection{Word Decoding Fluency (WD)}

A non-word reading fluency test was designed for this study. It contains 30 vowelized non-words for second grade students, and 50 vowelized non-words for fourth grade students that are two to three syllables long. Non-words must be read following a phonological procedure since they are not represented in the mental lexicon and differ from other kinds of pseudowords. The non-words can be read despite the fact that they do not follow the typical phonotactic rules of word building in Arabic. The child was allowed to have three practice items and then instructed to read these non-words as quickly as possible. The non-word stimuli were presented on one sheet in ten rows with three items (second grade) and five items (fourth grade) in each row. The test was stopped after $1 \mathrm{~min}$ and the final score was calculated based on the number of correct non-words read per minute. The Cronbach's alpha for the second grade 30 items was (0.97) and for the fourth grade 50 items was $(0.99)$.

\subsubsection{Reading Comprehension (RC)}

An oral reading fluency test was designed. It contains a narrative text representing graded levels of difficulty for second and fourth grade students. The text included the most frequent words and simple sentence structures, and progressed to less frequently used words with longer and more complex sentence structures. All words were vowelized because this was a comprehension measure and having all words vowelized would control for other aspects of word recognition such as, in the case of devowelization, contextual cues that would help identify words. Second grade text consisted of five lines whereas fourth grade text was 8 lines long. After reading the text the students were asked 11 questions. The Cronbach's alpha for second grade text was (0.92) and for fourth grade text was (0.91).

\subsubsection{Listening Comprehension (LC)}

A listening comprehension test was designed especially for this study. The test included a story text to which the student listened. After listening six questions are posed to elicit answers. The story text for the second grade consisted of five lines with simple words used whereas the story text for the fourth grade consisted of six lines with more difficult words introduced. The test was not timed. The tester would stop after he recorded the student's answers to the questions. The Cronbach's alpha was (0.71) for the second grade story text and (0.56) for the fourth grade story text. 


\subsubsection{Phonological Awareness (PA)}

Two subtests were developed to measure PA skills, the phoneme segmentation (PS) and phoneme blending (PB) in words. The PS subtest contained a list of 20 items of increasing difficulty. The segmentation became more difficult as participants were required to drop out increasingly smaller segments of greater phonological complexity. Items progressed in difficulty. For the practice items, we added two more trials so that children could comprehend the instructions and task requirements. The Cronbach's alpha was $(0.96)$ for the second grade test and (0.92) for the fourth grade test. The items in the PB subtest were also ordered by level of difficulty, according to word frequency, and following the same scheme employed for segmentation, progressing from syllables to phonemes. The correct answers represented real words in order to make scoring easier and to make the task more comprehensible for students. The test contained 20 items. The practice items consisted of three practice words to ensure that children comprehended the required task. Cronbach's alpha for the second grade 20 test items was (0.96) and for the fourth grade20 test itmes was (0.96).

\section{Results}

A three way MANOVA was conducted to examine the differences and variations in the measured reading skills in addition to the effects of condition (ARDs vs. NA), gender (males vs. females), and Grade level (grade two vs. grade four) on students' reading skills. Further, we examined the effects of the interaction between the three independent variables, namely condition, gender and grade level. Means and standard deviation of the participants on the reading skills measures were calculated for both students at risk for RDs and NA students (See Table 2).

Table 2. Means and Standard Deviations on the dependent measures

\begin{tabular}{|c|c|c|c|c|c|c|c|c|c|c|c|c|c|c|c|c|c|}
\hline \multirow{2}{*}{ Gender } & \multirow{2}{*}{$\begin{array}{c}\text { Grad } \\
\mathrm{e}\end{array}$} & \multirow{2}{*}{$\begin{array}{c}\text { Conditi } \\
\text { on }\end{array}$} & \multirow[t]{2}{*}{$\mathrm{N}$} & \multicolumn{2}{|c|}{ LSI } & \multicolumn{2}{|c|}{ WD } & \multicolumn{2}{|c|}{ PS } & \multicolumn{2}{|c|}{ PB } & \multicolumn{2}{|c|}{ WR } & \multicolumn{2}{|c|}{$\mathrm{RC}$} & \multicolumn{2}{|c|}{ LC } \\
\hline & & & & $\mathrm{M}$ & SD & M & SD & $\mathrm{M}$ & SD & M & SD & M & SD & $\mathrm{M}$ & SD & M & SD \\
\hline \multirow{11}{*}{ Male } & \multirow[t]{3}{*}{2} & ARD & 46 & 34.8 & 28.8 & 9.35 & 16.2 & 15.0 & 20.9 & 41.5 & & 18.9 & & 13.0 & & 83.7 & \\
\hline & & & 30 & & & 3.8 & & & & & & 9.8 & & & & & 12.1 \\
\hline & & Total & 76 & 52.7 & 36.8 & 28.9 & 35.3 & 33.7 & 36.8 & 58.3 & 39.0 & 39.0 & 38.9 & 28.2 & 34.8 & 37.2 & 18.8 \\
\hline & \multirow[t]{3}{*}{4} & ARD & 85 & 62.2 & 32.2 & 10.9 & 13.8 & 26.2 & 23.9 & 43.2 & 30.6 & 36.4 & 31.5 & 20.2 & 23.9 & 62.1 & 31.3 \\
\hline & & NA & 48 & 83.2 & 27.1 & 45.7 & 31.6 & 66.0 & 35.3 & 76.2 & 25.8 & 76.6 & 30.9 & 44.2 & 31.8 & 86.8 & 15.7 \\
\hline & & To & & & 2.0 & 3.5 & .5 & 0.6 & & & 3.0 & 50.9 & 36.7 & 3.9 & 9.2 & 1.0 & 29.2 \\
\hline & Tota & ARI & & & .6 & .4 & 4.6 & 22.2 & & 2.6 & & 30.2 & 30.6 & 7.7 & .5 & 9.7 & 30.0 \\
\hline & \multirow[t]{2}{*}{1} & & & & 8.3 & 50.7 & 33.7 & 64.6 & 36.1 & .2 & 26.9 & 74.0 & 32.8 & 7.0 & 4.2 & 9.1 & 14.6 \\
\hline & & & & 3.6 & 4.8 & 5.4 & 30.6 & 38.1 & 35.3 & 6.3 & 35.2 & 46.6 & 37.9 & 8.6 & 3 & 6.9 & 27.0 \\
\hline & \multirow[t]{3}{*}{2} & & & 48.1 & 30.1 & 14.4 & 22.1 & 13.4 & & 6.0 & 35.6 & 25.8 & 30.7 & 5.1 & 9.9 & 4.2 & \\
\hline & & & & & & & & 76.1 & & & & 2.2 & 21.0 & .0 & & 9.9 & 18.8 \\
\hline \multirow{7}{*}{$\begin{array}{c}\text { Fema } \\
\text { le }\end{array}$} & & & & & & 9.4 & & 47.0 & & & 37.0 & 56.0 & 38.3 & .6 & 8.0 & 2.6 & 25.1 \\
\hline & \multirow[t]{3}{*}{4} & ARD & 45 & 65.1 & 29.4 & 13.2 & 18.1 & 28.3 & 27.8 & 47.2 & 28.9 & 39.7 & 29.3 & 18.3 & 18.5 & 61.9 & 28.4 \\
\hline & & & 52 & 92.6 & 5.4 & 7.1 & 32.8 & 79.3 & 28.2 & 0.1 & 13.4 & 94.3 & 15.7 & 64.9 & 2.9 & 1.3 & 17.3 \\
\hline & & & 1 & & 26.9 & 1.0 & 37.9 & 54.6 & 37.8 & 69.3 & 31.0 & 67.8 & 35.9 & 42.3 & 5.5 & 77.0 & 27.5 \\
\hline & Tota & ARD & & & 0.7 & 3.7 & 19.6 & 22.3 & & 2.7 & 2.1 & 34.1 & 30.5 & 7.0 & 9.0 & 6.8 & 29.1 \\
\hline & \multirow[t]{2}{*}{1} & & & & & & & & & & & 89.2 & 19.0 & & & 0.7 & 17.8 \\
\hline & & & & & 29.2 & 0.3 & 37.0 & 51.4 & 39.0 & 66.8 & 33.6 & 62.9 & 37.2 & 40.8 & 6.1 & 79.3 & 26. \\
\hline \multirow{9}{*}{ Total } & \multirow[t]{3}{*}{2} & ARD & 79 & 40.3 & 29.9 & 11.4 & 18.9 & 14.3 & 20.9 & 39.2 & 35.7 & 21.8 & 27.8 & 13.9 & 21.1 & 79.7 & 25. \\
\hline & & NA & 68 & 84.6 & 24.6 & 0.1 & 33.1 & 70.1 & 33 & 5.8 & 22.1 & 76.8 & 28.9 & 55.7 & 7.0 & 91.1 & 16. \\
\hline & & & & & 35.3 & 3.9 & 35.9 & 40.1 & & 0.7 & & 47.2 & 39.4 & 33.2 & 6.1 & 5.0 & 22. \\
\hline & \multirow[t]{3}{*}{4} & AR & & 63 & 31 & 11 & 15 & 27 & & & & 37.6 & 30.7 & & & 2.0 & 30. \\
\hline & & & & & 22.2 & 56.8 & 33 & 72 & & & & 85.8 & 25.6 & & & 9.1 & 16 \\
\hline & & Total & & 73 & 30.2 & 31.0 & 33.5 & 46.6 & & & 32.8 & 58.2 & 37.2 & 4.7 & & 3.6 & \\
\hline & \multirow[t]{3}{*}{ Tota } & ARD & 21 & 54.8 & 32.6 & 11.6 & 16.8 & 22.3 & 24.5 & 42.6 & 32.2 & 31.7 & 30.5 & 17.4 & 21.8 & 68.6 & 29. \\
\hline & & NA & 16 & 86.7 & 23.2 & 58.2 & 33.5 & 71.8 & 32.7 & & 21.6 & 82.1 & 27.3 & 55.3 & 35.0 & 89.9 & 16. \\
\hline & & Total & 38 & 68.8 & 32.9 & 32.1 & 34.4 & 44.1 & 37.6 & 61.0 & 34.9 & 54.0 & 38.4 & 34.1 & 34.0 & 78.0 & \\
\hline
\end{tabular}

Note: $\mathrm{NA}=$ Normally Achieving pupils; ARDs $=$ At Risk for Reading Disabilities, $\mathrm{N}=$ Number of Participants, $\mathrm{M}=$ Mean, $\mathrm{SD}=$ Standard Deviation

Gender, condition and grade were all entered into the MANOVA independent variable and the reading skills as dependent variables. As shown in tables 3 and 4 the main effect of gender was significant, Wilks' $\lambda=.950, F_{(7,367)}$ 
$=2.7, \mathrm{p}<.009, \eta \mathrm{p}^{2}=.050$. Compared to males, females attained higher scores on LSI $\left(F_{(1,373)}=7.999, p=.001\right.$, $\left.\eta \mathrm{p}^{2}=.021\right), \mathrm{WD}\left(F_{(1,373)}=8.342, p=.001, \eta \mathrm{p}^{2}=.022\right), \operatorname{PS}\left(F_{(1,373)}=5.296, p=.05, \eta \mathrm{p}^{2}=.014\right), \mathrm{WR}\left(F_{(1,373)}=\right.$ $\left.11.121, p=.001, \eta \mathrm{p}^{2}=.029\right)$, and $\mathrm{RC}\left(F_{(1,373)}=5.575, p=.01, \eta \mathrm{p}^{2}=.015\right)$. Grade (grade two vs. grade 4) was also significant, Wilks' $\lambda=.809, F_{(7,367)}=12.39, \mathrm{p}<.001, \eta \mathrm{p}^{2}=.191$. Compared to second grade students, fourth grade students scored higher on LSI $\left(F_{(1,373)}=19.415, p=.001, \eta p^{2}=.049\right)$, PS $\left(F_{(1,373)}=7.488, p=.001, \eta p^{2}\right.$ $=.020), \mathrm{WR}\left(F_{(1,373)}=17.262, p=.001, \eta \mathrm{p}^{2}=.044\right)$, and LC $\left(F_{(1,373)}=14.041, p=.001, \eta \mathrm{p}^{2}=.036\right)$. Condition (ARDs vs. NA) was also significant, Wilks' $\lambda=.488, F_{(7,367)}=55.07, \mathrm{p}<.001, \eta \mathrm{p}^{2}=.512$. Compared to students ARDs, NA students attained higher scores on LSI $\left(F_{(1,373)}=128.683, p=.001, \eta \mathrm{p}^{2}=.257\right)$, WD $\left(F_{(1,373)}=\right.$ $\left.295.175, p=.001, \eta \mathrm{p}^{2}=.442\right)$, PS $\left(F_{(1,373)}=281.071, p=.001, \eta \mathrm{p}^{2}=.430\right), \operatorname{PB}\left(F_{(1,373)}=200.215, p=.001, \eta \mathrm{p}^{2}\right.$ $=.349), \mathrm{WR}\left(F_{(1,373)}=280.466, p=.001, \eta \mathrm{p}^{2}=.429\right), \operatorname{RC}\left(F_{(1,373)}=161.762, p=.001, \eta p^{2}=.302\right)$, and LC $\left(F_{(1,}\right.$ 373) $\left.=59.148, p=.001, \eta p^{2}=.137\right)$.

Table 3. Wilkis Lambda Test of the effect of gender, grade level and condition on participants' reading skills

\begin{tabular}{lllllll}
\hline Effect & Value & $\mathrm{F}$ & $\mathrm{df}$ & Error df & Sig. & Eta Squared \\
\hline Gender (A) & .950 & 2.732 & 7 & 367 & .009 & .050 \\
Grade (B) & .809 & 12.391 & 7 & 367 & .000 & .191 \\
Condition (C) & .488 & 55.068 & 7 & 367 & .000 & .512 \\
A B & .967 & 1.768 & 7 & 367 & .092 & .033 \\
A C & .975 & 1.326 & 7 & 367 & .236 & .025 \\
$\mathrm{~B} * \mathrm{C}$ & .924 & 4.323 & 7 & 367 & .000 & .076 \\
$\mathrm{~A} * \mathrm{~B} * \mathrm{C}$ & .958 & 2.320 & 7 & 367 & .025 & .042 \\
\hline
\end{tabular}

For the interaction between gender and grade level as well as between gender and condition, the results revealed no significant effects. Alternatively, however, the interaction between grade level and condition showed significant effects, Wilks' $\lambda=.924, F_{(7,367)}=4.32, \mathrm{p}<.001, \eta \mathrm{p}^{2}=.076$. Compared to other condition and grade level students, NA second grade students scored the highest scores on $\operatorname{LSI}\left(F_{(1,373)}=9.769, p=.001, \eta p^{2}=.026\right)$ and $\operatorname{LC}\left(F_{(1,373)}=8.189, p=.001, \eta p^{2}=.021\right)$ whereas fourth grade students scored the highest scores on LSI only. The interaction between gender, grade level and condition was also significant, Wilks' $\lambda=.958, F_{(7,367)}=$ $2.32, \mathrm{p}<.025, \eta \mathrm{p}^{2}=.042$. The differences were only in $\operatorname{WD}\left(F_{(1,373)}=4.203, p=.05, \eta \mathrm{p}^{2}=.011\right)$, with NA female fourth grade students scoring the highest scores whereas ARDs male second grade students scored the lowest scores.

Table 4. Significant multivariate effects of gender, grade level, and condition on participants' reading skills (at $\mathrm{p}<.001$ level)

\begin{tabular}{|c|c|c|c|c|c|c|c|}
\hline Source & $\begin{array}{l}\text { Dependent } \\
\text { Variable }\end{array}$ & $\begin{array}{l}\text { Sum of } \\
\text { Squares }\end{array}$ & df & Mean Square & $\mathrm{F}$ & Sig. & Eta Squared \\
\hline \multirow{7}{*}{$\begin{array}{l}\text { Gender } \\
\text { (A) }\end{array}$} & LSI & 6053.53 & 1 & 6053.53 & 7.999 & .005 & .021 \\
\hline & WD & 5256.12 & 1 & 5256.12 & 8.342 & .004 & .022 \\
\hline & PS & 4137.52 & 1 & 4137.52 & 5.296 & .022 & .014 \\
\hline & PB & 1294.34 & 1 & 1294.34 & 1.656 & .199 & .004 \\
\hline & WR & 8816.67 & 1 & 8816.67 & 11.121 & .001 & .029 \\
\hline & $\mathrm{RC}$ & 4381.98 & 1 & 4381.98 & 5.575 & .019 & .015 \\
\hline & LC & 350.69 & 1 & 350.69 & .614 & .434 & .002 \\
\hline \multirow{7}{*}{$\begin{array}{l}\text { Grade } \\
\text { (B) }\end{array}$} & LSI & 14693.13 & 1 & 14693.13 & 19.415 & .000 & .049 \\
\hline & WD & 246.36 & 1 & 246.36 & .391 & .532 & .001 \\
\hline & PS & 5850.01 & 1 & 5850.01 & 7.488 & .007 & .020 \\
\hline & PB & 353.92 & 1 & 353.92 & .453 & .501 & .001 \\
\hline & WR & 13685.87 & 1 & 13685.87 & 17.262 & .000 & .044 \\
\hline & $\mathrm{RC}$ & 443.88 & 1 & 443.88 & .565 & .453 & .002 \\
\hline & LC & 8022.83 & 1 & 8022.83 & 14.041 & .000 & .036 \\
\hline \multirow{4}{*}{$\begin{array}{l}\text { Condition } \\
\text { (C) }\end{array}$} & LSI & 97384.90 & 1 & 97384.90 & 128.683 & .000 & .257 \\
\hline & WD & 185973.23 & 1 & 185973.23 & 295.175 & .000 & .442 \\
\hline & PS & 219580.48 & 1 & 219580.48 & 281.071 & .000 & .430 \\
\hline & PB & 156483.29 & 1 & 156483.29 & 200.215 & .000 & .349 \\
\hline
\end{tabular}




\begin{tabular}{|c|c|c|c|c|c|c|c|}
\hline & WR & 222360.16 & 1 & 222360.16 & 280.466 & .000 & .429 \\
\hline & $\mathrm{RC}$ & 127148.93 & 1 & 127148.93 & 161.762 & .000 & .302 \\
\hline & $\mathrm{LC}$ & 33796.61 & 1 & 33796.61 & 59.148 & .000 & .137 \\
\hline & LSI & 7392.66 & 1 & 7392.66 & 9.769 & .002 & .026 \\
\hline & WD & 307.87 & 1 & 307.87 & .489 & 485 & .001 \\
\hline & PS & 2053.28 & 1 & 2053.28 & 2.628 & 106 & .007 \\
\hline \multirow[t]{7}{*}{$B * C$} & PB & 1708.61 & 1 & 1708.61 & 2.186 & .140 & .006 \\
\hline & WR & 857.72 & 1 & 857.72 & 1.082 & .299 & .003 \\
\hline & $\mathrm{RC}$ & 769.54 & 1 & 769.54 & .979 & .323 & .003 \\
\hline & $\mathrm{LC}$ & 4679.13 & 1 & 4679.13 & 8.189 & .004 & .021 \\
\hline & LSI & 777.75 & 1 & 777.75 & 1.028 & .311 & .003 \\
\hline & WD & 2648.19 & 1 & 2648.19 & 4.203 & .041 & .011 \\
\hline & PS & 89.01 & 1 & 89.01 & .114 & .736 & .000 \\
\hline \multirow[t]{7}{*}{$A * B * C$} & PB & 12.77 & 1 & 12.77 & .016 & .898 & .000 \\
\hline & WR & 430.94 & 1 & 430.94 & .544 & 461 & .001 \\
\hline & $\mathrm{RC}$ & 1588.62 & 1 & 1588.62 & 2.021 & .156 & .005 \\
\hline & LC & 17.53 & 1 & 17.53 & .031 & .861 & .000 \\
\hline & LSI & 282280.11 & 373 & 756.78 & & & \\
\hline & WD & 235006.14 & 373 & 630.04 & & & \\
\hline & PS & 291397.49 & 373 & 781.22 & & & \\
\hline \multirow[t]{4}{*}{ Error } & PB & 291528.535 & 373 & 781.578 & & & \\
\hline & WR & 295723.810 & 373 & 792.825 & & & \\
\hline & $\mathrm{RC}$ & 293187.377 & 373 & 786.025 & & & \\
\hline & $\mathrm{LC}$ & 213128.259 & 373 & 571.389 & & & \\
\hline
\end{tabular}

Note: $\mathrm{LSI}=$ Letter sound identification, $\mathrm{WD}=$ word decoding, $\mathrm{PS}=$ phoneme segmentation, $\mathrm{PB}=$ phoneme blending, $\mathrm{WR}=$ word recognition, $\mathrm{RC}=$ reading comprehension, $\mathrm{LC}=$ Listening comprehension

\section{Discussion}

This study had two purposes. The first was to investigate the effect of gender, grade level, and student condition on the acquisition of a number of critical reading skills of Arabic, namely letter sound identification, word decoding, phonological awareness, word recognition, reading comprehension and listening comprehension. The second was to examine the interaction effect of these variables on students' acquisition of critical reading skills of learning Arabic. The rationale of the study lies in that knowledge about the causes, correlates, and predictors of children's reading success and reading failure in the early elementary grades has become a priority for educational systems (Snow, Burns, \& Griffin, 1998). This knowledge has been incorporated into methods of identifying, monitoring, and helping struggling readers in the elementary school grades.

The study results indicated that gender, grade level, and condition had an effect on students' acquisition of reading skills. Males outperformed females; fourth grade students outperformed second grade students; and NA students outperformed students at risk for RD. These results echo similar results from previous studies. The issue of gender is one important are in reading research. Researchers have advocated that gender differences in educational outcome are of great concern for many societies as many questions need to be posed when females and males appear unequally able to attain benefit from the investment in education (Rosén, 2001; Wagemaker, 1996). Particular interest has been paid to gender differences in reading as reading plays a key role in academic achievement (Rosén, 2001). Our results showed that males outperformed females in all tested reading skills except for PB, which is a phonological awareness skill. Previous studies showed that students' performance on different PA skills may vary from a language to anther due to the idiosyncratic nature of the language orthography (Kim, Kim, \& Lee, 2007; Torgesen,, Wagner, Rashotte, Burgess, \& Hecht, 1997). Our results indicate that gender may also be considered a contributing factor to the variation of students' performance on PA measures. 

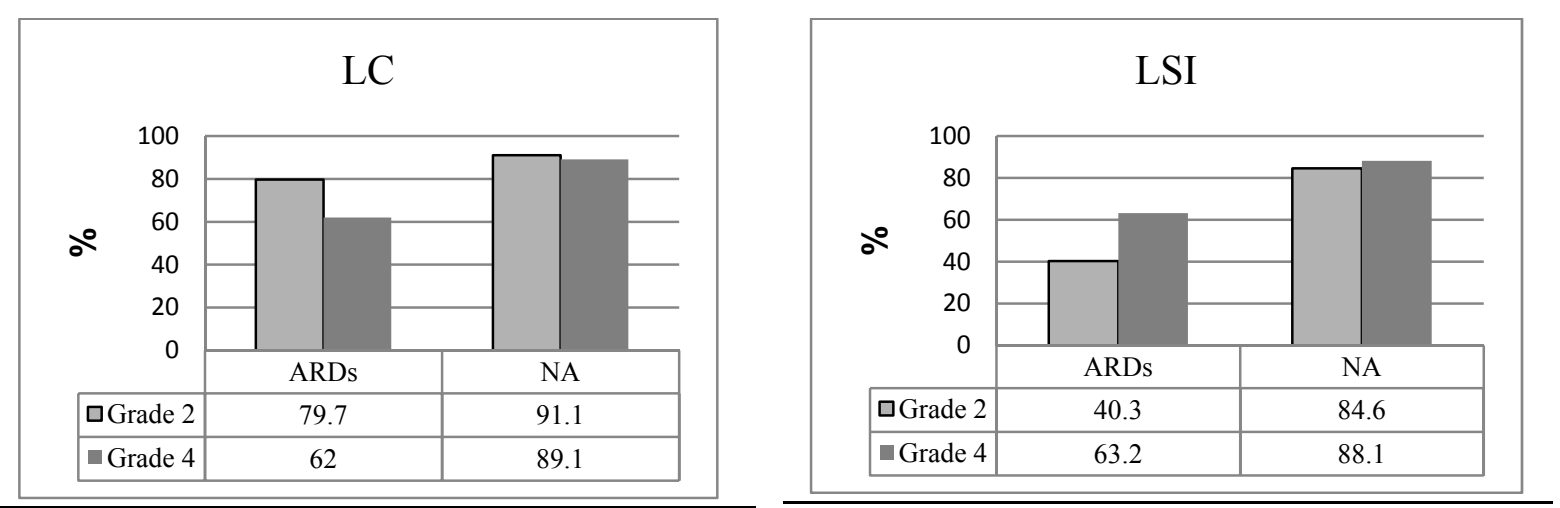

Figure1. Effect of the interaction between grade level and student condition on participants' performance on reading measures

For grade level, fourth grade students outperformed second grade students in all measured skills except for WD, $\mathrm{PB}$, and RC. This variation is interesting in some aspects. Previous studies have shown that variation in reading skills is important for identifying reading problems (Kim et al., 2007). It seems that PB, WD, and RC cannot be counted on for identifying reading problems in early grades as in grade1. As for student condition, as expected NA students outperformed students at risk for RDs in all reading skills assessed in our study. These results support the view that children's skills related to print knowledge (e.g., alphabet knowledge), phonological processing skills (i.e., phonological awareness, phonological access to lexical store, phonological memory), and aspects of oral language (e.g., vocabulary, word knowledge) are substantive and independent predictors of children's later reading outcomes (Lonigan et al., 2008). Further, children at risk for RD can be identified based on testing these reading skills as early as in first or second grade. This has been supported by longitudinal studies which revealed a high degree of continuity between the levels of reading skills displayed at early grades and the levels of reading skills displayed by these children when they are in higher grades (e.g., Storch \& Whitehurst, 2002; Lonigan, Burgess, \& Anthony, 2000;), indicating that the developmental antecedents that underlie the acquisition of reading are found early and prior to the onset of formal schooling.

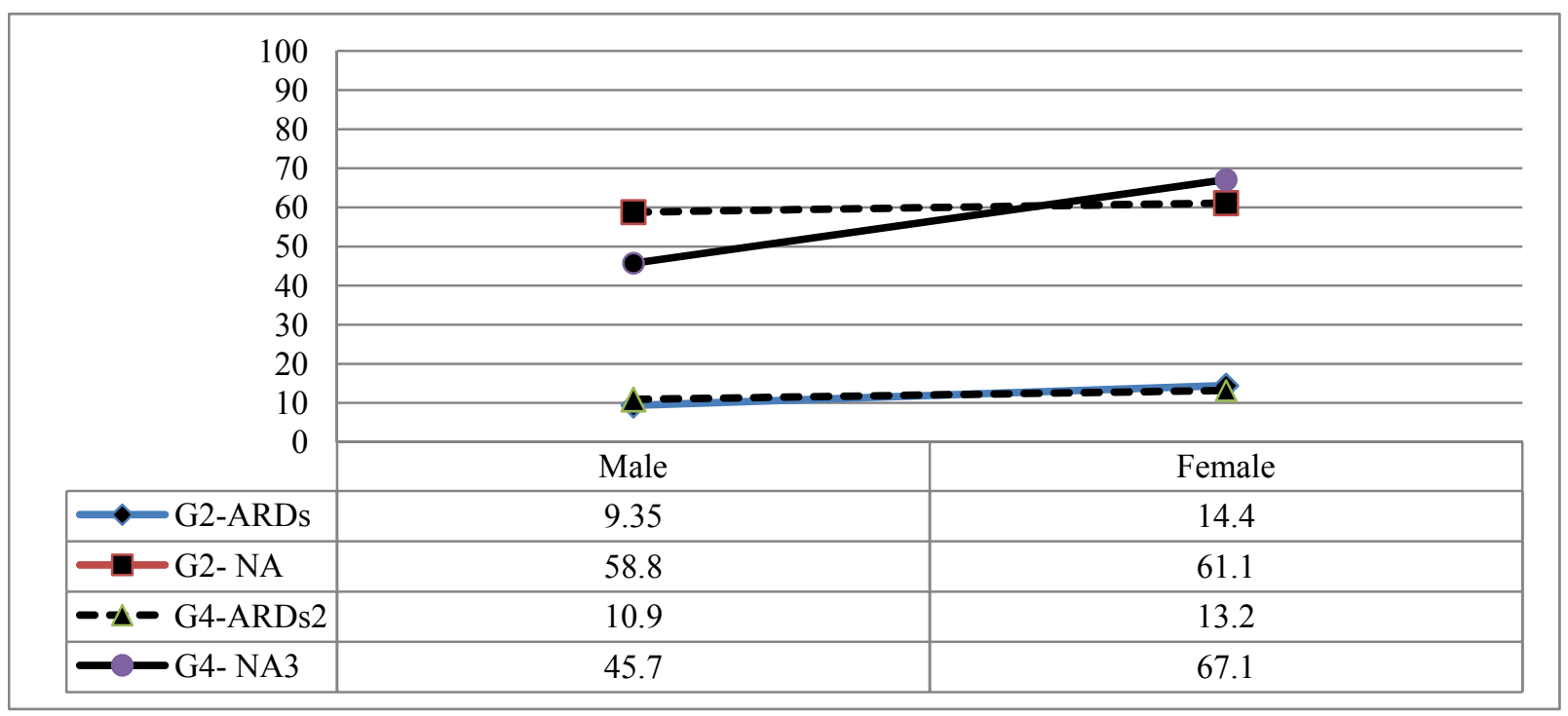

Figure 2. Effect of the interaction between gender, grade level and condition on participants' performance on reading measures

As for the interaction effect of the variables of gender, grade level and student condition on students' reading skills, our study results showed that there is not interaction effect between gender and grade level, while there was an effect of both grade level and student condition and the three variables together. As shown in figure 1 the interaction effect was significant in LSI and LC in favour of NA second grade students while it was significant in LC only in favour of NA fourth grade students. This reflects the fact that LSI and LC may be very crucial in 
identifying children at risk for RD when they are learning Arabic. These results reflect previous studies which showed that in alphabetic languages, the skill of matching the sound with the letters is key predictor of the student's future reading performance. This is simply because the LSI combines both PA skills and alphabet knowledge (Abu Rabia, 2012, 2001, 1997). In fact the positive roles of phonological awareness and letter knowledge in word-level processes in Arabic are not surprising, given the alphabetic nature of Arabic. One interesting finding of this interaction is that it was not significant for PA skills, i.e. PS and PB. One explanation for this is that it is likely that teaching Arabic in schools in Oman focus less on teaching these skills in early grades in elementary schools in Oman. The finding that the interaction was significant for LD reflects findings from previous studies which showed that broader language skills contribute to children's reading performance (Fraser, J., \& Conti-Ramsden, 2008).

The interaction effect of the three variables together was significant for WD. NA female fourth grade students scored the highest whereas male second grade students at risk for RD scored the lowest (figure2). This finding shows that WD can be a quick screener for identifying struggling readers for both males and females in early grades. One of the theoretical models of reading that has received much theoretical and empirical attention in English is the simple view of reading (Gough \& Tunmer, 1986). According to this view, reading comprehension is a product of listening comprehension and decoding. The interaction of grade level and student condition showed that LC was significant while the interaction of the three variables together showed WD was significant. According to Kim \& Pallante (2012), decoding can be word reading (or word recognition) and/or phonological decoding (e.g., non-word reading). In the current study we relied on the second type. Phonological coding depends more on the grapheme-phoneme correspondence knowledge whereas word reading would draw on semantic and orthographic processes (Kim \& Pallante, 2012). Phonological decoding fluency (i.e., nonsense word fluency) has been shown to be related to reading comprehension in a few studies with English-speaking children (Fien et al., 2008; cited in Kim \& Pallante, 2012).

\section{Conclusion}

The study adds to the literature on the key skills which can play a key role in the learning of alphabetic language other than English. The Arabic language is a language with rich orthography and therefore there is a need to understand how such richness can inform practitioners and researchers in highlighting the key features which may enable teachers to identity poor and skilled readers. Our findings indicate that there are variations in reading skills profile of NA and at risk for RD students in second and fourth grades. The variations were evident in the effects of gender, grade level and student condition as well as in the interaction effects, suggesting the complexity of the Arabic reading skills. Future research needs to focus on growth trajectories of Arabic reading skills from early to later grades in elementary schools.

\section{Acknowledgments}

This research was funded by the His Majesty's Research Trust Fund (HMRTF) at Sultan Qaboos University under grant No. (SR/EDU/PSYC/12/01). The authors, therefore, acknowledge with thanks HMRTF technical and financial support.

\section{References}

Abu Rabia, S. (1995). Learning to read in Arabic: Reading, syntactic, orthographic and working memory skills in normally achieving and poor Arabic readers. Reading Psychology: An International Quarterly, 16(4), 351-394. http://dx.doi.org/10.1080/0270271950160401

Abu-Rabia, S. (1997). Reading in Arabic orthography: The effect of vowels and context on reading accuracy of poor and skilled native Arabic readers. Reading and Writing: An Interdisciplinary, 9(1), 65-78.

Abu-Rabia, S. (2001). The role of vowels in reading Semitic scripts: Data from Arabic and Hebrew. Reading and Writing: An Interdisciplinary Journal, 14, 39-59

Abu-Rabia, S. (2012). The Role of Morphology and Short Vowelization in Reading Morphological Complex Words in Arabic: Evidence for the Domination of the Morpheme/Root-Based theory in Reading Arabic. Creative Education, 3(4), 486-494. http://dx.doi.org/10.4236/ce.2012.34074

Abu-Rabia, S., Share, D., \& Mansour, M. S. (2003). Word recognition and basic cognitive processes among reading-disabled and normal readers in Arabic. Reading and Writing, 16(5), 423-442.

Al Otaiba, S., \& Fuchs, D. (2002). Characteristics of Children Who Are Unresponsive to Early Literacy Intervention A Review of the Literature. Remedial and Special Education, 23(5), 300-316. http://dx.doi.org/10.1177/07419325020230050501 
Al Otaiba, S., \& Fuchs, D. (2006). Who are the young children for whom best practices in reading are ineffective? An experimental and longitudinal study. Journal of Learning Disabilities, 39(5), 414-431. http://dx.doi.org/10.1177/00222194060390050401

Azzam, R. (1993). The nature of Arabic reading and spelling errors of young children. Reading and Writing, 5(4), 355-385.

Bryant, P. (1998). Sensitivity to onset and rhyme does predict young children's reading: A comment on Muter, Hulme, Snowling, and Taylor. Journal of Experimental Child Psychology, 71(1), 29-37. http://dx.doi.org /10.1006/jecp.1998.2455

Cunningham, A. E., \& Stanovich, K. E. (1998). Early reading acquisition and its relation to reading experience and ability 10 years later. Developmental Psychology, 33, 934-945. http://dx.doi.org/10.1037//0012 $-1649.33 .6 .934$

de Jong, P. F., \& van der Leij, A. (1999). Specific contributions of phonological abilities to early reading acquisition: Results from a Dutch latent variable longitudinal study. Journal of Educational Psychology, 91, 450-476. http://dx.doi.org/10.1037//0022-0663.91.3.450

Dickinson, D., McCabe, A., Anastasopoulos, L., Peisner-Feinberg, E., \& Poe, M. (2003). The comprehensive language approach to early literacy: The interrelationships among vocabulary, phonological sensitivity, and print knowledge among preschool-aged children. Journal of Educational Psychology, 95, 465-481. http://dx.doi.org/10.1037/0022-0663.95.3.465

Elbeheri, G. (2005). Dyslexia in Egypt. In I. Smythe, J. Everatt, \& R. Salter (Eds.), The International Book of Dyslexia: A Guide to Practice and Resources (pp. 79-85). UK, Wileys.

Elbeheri, G., \& Everatt, J. (2007). Literacy ability and phonological processing skills amongst dyslexic and non-dyslexic speakers of Arabic. Reading and writing, 20(3), 273-294. http://dx.doi.org/10.1007 /s11145-006-9031-0

Emam, M. (2012). The development of an optimal framework for the identification and intervention of pupils with RDs in elementary schools in the Sultanate of Oman. Strategic Research Proposal funded by His Majesty's Trust Fund, Sultan Qaboos University, (SR/EDU/PSYC/12/01).

Francis, D. J., Shaywitz, S. E., Stuebing, K. K., Shaywitz, B. A., \& Fletcher, J. M. (1996). Developmental lag versus deficit models of reading disability: A longitudinal individual growth curve analysis. Journal of Educational Psychology, 88, 3-17. http://dx.doi.org/ 10.1037/0022-0663.88.1.3

Fraser, J., \& Conti-Ramsden, G. (2008). Contribution of phonological and broader language skills to literacy. International Journal of Language \& Communication Disorders, 43(5), 552-569. http://dx.doi.org/10.1080 $/ 13682820701778069$

Gillon, G. T. (2004). Phonological awareness: From research to practice. New York, NY: The Guilford Press.

Goswami, U. (2001). Rhymes are important: A comment on Savage. Journal of Research in Reading, 24(1), 19-29. http://dx.doi.org/10.1111/1467-9817.00130

Gough, P. B., \& Tunmer, W. E. (1986). Decoding, reading, and reading disability. Remedial and Special Education, 7, 6-10. http://dx.doi.org/10.1177/074193258600700104

Goulandris, N. (2003). Dyslexia in different languages: Cross-linguistic comparisons. London, UK: Whurr.

Hulme, C., Hatcher, P. J., Nation, K., Brown, A., Adams, J., \& Stuart, G. (2002). Phoneme awareness is a better predictor of early reading skill than onset-rime awareness. Journal of experimental child psychology, 82(1), 2-28. http://dx.doi.org/10.1006/jecp.2002.2670

Kim, D., Kim, W., \& Lee, K. (2007). The relationship between phonological awareness and early reading for first grade Korean language learners with reading difficulties. Asia Pacific Education Review, 8(3), 426-434. http://dx.doi.org/10.1007/BF03026471

Kim, Y. S., \& Pallante, D. (2012). Predictors of reading skills for kindergartners and first grade students in Spanish: A longitudinal study. Reading and Writing, 25(1), 1-22. http://dx.doi.org/10.1007/s11145 $-010-9244-0$

Kim, Y. -S. (2009). The foundation of literacy skills in Korean: The relationship between letter-name knowledge and phonological awareness and their relative contribution to literacy skills. Reading and Writing: An Interdisciplinary Journal, 22, 907-931. http://dx.doi.org/10.1007/s11145-008-9131-0. 
Lonigan, C. J., Allan, N. P., \& Lerner, M. D. (2011). Assessment of preschool early literacy skills: Linking children's educational needs with empirically supported instructional activities. Psychology in the Schools, 48(5), 488-501. http://dx.doi.org/10.1002/pits.20569

Lonigan, C. J., Burgess, S. R., \&Anthony, J. L. (2000). Development of emergent literacy and early reading skills in preschool children: Evidence from a latent variable longitudinal study. Developmental Psychology, 36, 596-613. http://dx.doi.org/10.1037//0012-1649.36.5.596

Lonigan, C. J., Schatschnieder, C., \& Westberg, L. (2008). Impact of code-focused interventions on young children's early literacy skills. In Developing early literacy: Report of the National Early Literacy Panel (pp. 107-151). Washington, DC: National Institute for Literacy.

Mahfoudhi, A., Elbeheri, G., Al-Rashidi, M., \& Everatt, J. (2010). The role of morphological awareness in reading comprehension among typical and learning disabled native Arabic speakers. Journal of learning disabilities, 43(6), 500-514. http://dx.doi.org/10.1177/0022219409355478

Muter, V., Hulme, C., Snowling, M. J., \& Stevenson, J. (2004). Phonemes, rimes and language skills as foundations of early reading development: Evidence from a longitudinal study. Developmental Psychology, 40, 663-681. http://dx.doi.org/10.1037/0012-1649.40.5.665

Rosén, M. (2001). Gender differences in reading performance on documents across countries. Reading and Writing, 14(1-2), 1-38.

Saiegh-Haddad, E. (2003). Linguistic distance and initial reading acquisition: The Case of Arabic diglossia. Applied Psycholinguistics, 24(3), 431-451. http://dx.doi.org/10.1017/S0142716403000225

Share, D. L., Jorm, A. F., Maclean, R., \& Matthews, R. (1984). Sources of individual differences in reading acquisition. Journal of Educational Psychology, 76, 1309-1324. http://dx.doi.org/10.1037//0022 $-0663.76 .6 .1309$

Snow, C. E., Burns, M. S., \& Griffin, P. (Eds.). (1998). Preventing reading difficulties in young children. Washington, D.C.: National Academy Press.

Snowling, M. J. (2000). Dyslexia (2nd ed.). Malden, MA: Blackwell Publishing.

Storch, S. A., \& Whitehurst, G. J. (2002). Oral language and code-related precursors to reading: Evidence from a longitudinal structural model. Developmental Psychology, 38, 934-947. http://dx.doi.org/10.1037//0012 $-1649.38 .6 .934$

Tabors, P. O., Snow, C. E., \& Dickinson, D. K. (2001). Homes and schools together: Supporting language and literacy development. In D. K. Dickinson, \& P. O. Tabors (Eds.), Beginning literacy with language (pp. 313-334). Baltimore: Paul H. Brookes.

Tahan, S., Cline, T., \& Messaoud-Galusi, S. (2011). The relationship between language dominance and pre-reading skills in young bilingual children in Egypt. Reading and Writing, 24(9), 1061-1087. http://dx.doi.org/10.1007/s11145-011-9301-3

Taibah, N. J., \& Haynes, C. W. (2011). Contributions of phonological processing skills to reading skills in Arabic speaking children. Reading and Writing, 24(9), 1019-1042. http://dx.doi.org/10.1007/s11145-010-9273-8

Taouk, M., \& Coltheart, M. (2004). The cognitive processes involved in learning to read in Arabic. Reading and Writing, 17(1-2), 27-57. http://dx.doi.org/10.1023/B:READ.0000013831.91795.ec

Torgesen, J. K., Wagner, R. K., Rashotte, C. A., Burgess, S., \& Hecht, S. (1997). Contributions of phonological awareness and rapid automatic naming ability to the growth of word-reading skills in second- to fifth-grade children. Scientific Studies of Reading, 1(2), 161-185. http://dx.doi.org/10.1207/s1532799xssr0102_4

Wagemaker, H., (Ed.) (1996). Are girls better readers? Gender differences in reading literacy in 32 countries. The Hague: IEA.

Wagner, R. K., Torgesen, J. K., Rashotte, C. A., Hecht, S. A., Barker, T. A., Burgess, S. R., et al. (1997). Changing relations between phonological processing abilities and word-level reading as children develop from beginning to skilled readers: A 5-year longitudinal study. Developmental Psychology, 33, 468-479. http://dx.doi.org/10.1037//0012-1649.33.3.468

Whitehurst, G. J., \& Lonigan, C. J. (2001). Get Ready to Read! screening tool. New York, NY: National Center for Learning Disabilities. 


\section{Copyrights}

Copyright for this article is retained by the author(s), with first publication rights granted to the journal.

This is an open-access article distributed under the terms and conditions of the Creative Commons Attribution license (http://creativecommons.org/licenses/by/3.0/). 